\title{
Patterns of somatic distress among internally displaced persons in Ukraine: analysis of a cross-sectional survey
}

Draft date: 5 November 2018

Authors: Anson Cheung ${ }^{1}$, Nino Makhashvili ${ }^{2}$, Jana Javakhishvili ${ }^{2}$, Andrey Karachevsky ${ }^{3}$, Natalia Kharchenko ${ }^{4}$, Marina Shpiker ${ }^{4}$, Bayard Roberts ${ }^{* 1}$

${ }^{1}$ London School of Hygiene and Tropical Medicine (London, United Kingdom)

2 Ilia State University (Tbilisi, Georgia) and Global Initiative on Psychiatry (Tbilisi, Georgia)

${ }^{3}$ Shayk National Medical Academy (Kiev, Ukraine)

${ }^{4}$ Kiev International Institute of Sociology (Kiev, Ukraine)

*Corresponding author: Bayard Roberts (bayard.roberts@1shtm.ac.uk)

Postal address: Centre for Global Chronic Conditions, London School of Hygiene and Tropical Medicine, 15-17 Tavistock Place, London, United Kingdom, WC1H 9SH

Telephone: +44 (0)20 79272050

Word count: 3786 (excluding tables, figures, and references)

Tables and figures: 4 (plus Online Annex)

Acknowledgements and source of funding: We would like to thank the respondents participating in this study and the staff assisting with data collection for their contributions. This work was supported by a grant from the European Union's Instrument contributing to Stability and Peace (IcSP) under a project entitled "Psychosocial needs for peace: trauma rehabilitation and civic activism in Ukraine". The project was implemented by International Alert UK. The funder did not play a role in data collection, analysis, or interpretation.

Running head: Somatic distress among IDPs in Ukraine 


\section{Abstract}

Purpose: There are often high rates of mental disorders in low- and middle-income countries during humanitarian crises but the prevalence of somatic distress (SD) is underreported in existing health services research. We aim to examine patterns of SD among internally displaced persons (IDPs) in Ukraine, who were forcibly displaced due to the ongoing conflict in the country's eastern region.

Methods: The study design was a cross-sectional survey of 2203 adult IDPs throughout Ukraine. The survey collected data on sociodemographic characteristics, traumatic life events (Life Events Checklist), utilisation of mental health care services, and self-reported outcomes of SD (Patient Health Questionnaire 15), anxiety (Generalised Anxiety Disorder 7), depression (Patient Health Questionnaire 9), and post-traumatic stress (PTSD Checklist). Descriptive and multivariate regression analyses were used.

Results: Over half of respondents $(\mathrm{n}=1142,55 \%)$ were identified as being at risk of SD (PHQ-15 score $\geq 6)$ and the prevalence of moderate $(n=377,18 \%)$ and high severity SD risk $(\mathrm{n}=275,13 \%)$ was substantial. There were significant associations $(\mathrm{p}<0.05)$ between SD and age, female gender, economic status, self-reported depression and post-traumatic stress, and multiple trauma exposures. Being at risk of SD was also significantly associated with increased functional disability. Use of mental health care services was low across this population and only high SD risk seemed to be a reliable predictor of care-seeking behaviour.

Conclusions: There is a significant risk of SD among IDPs in Ukraine. Our results illustrate the need for targeted health services research and regional programs to ensure that mental health needs are appropriately met.

\section{Keywords}

Conflict, health services, IDPs, mental health, somatic distress, Ukraine

\section{Acronyms}

internally displaced person = IDP; post-traumatic stress disorder = PTSD; mental health and psychosocial support = MHPSS; somatic distress = SD; Patient Health Questionnaire $15=$ PHQ-15; Generalised Anxiety Disorder 7 = GAD-7; Patient Health Questionnaire $9=$ PHQ9; post-traumatic stress symptoms = PTSS; Post-Traumatic Stress Disorder Checklist for DSM-5 = PCL-5; World Health Organization Disability Assessment Schedule, version $2=$ WHODAS 2.0; Life Events Checklist = LEC-5; Kiev International Institute of Sociology = KIIS; odds ratio $=$ OR; confidence interval $=\mathrm{CI}$ 


\section{Introduction}

Armed conflict between the Ukrainian military and pro-Russian factions has led to instability in the eastern part of Ukraine, which shares a border with Russia. As of April 2016, there were an estimated 1.77 million internally displaced persons (IDPs) in Ukraine who have been forcibly removed from their homes [1]. Many of these IDPs have experienced high levels of exposure to violent and traumatic events, are currently living in temporary accommodation, have poor social support, and have low levels of employment [2]. All of these factors have been previously associated with poor mental health outcomes in post-conflict settings, increasing the risk of post-traumatic stress disorder (PTSD) and other common mental disorders such as anxiety and depression [3-5].

For crisis-affected populations currently living in Ukraine, there has been extremely limited qualitative research on the links between crisis-related adversity and mental health outcomes, with the majority of published work in this area focusing on the Holodomor, a period of mass starvation between 1932 and 1933 that caused millions of deaths [6]. Qualitative research has shown how the legacy of this famine defines collective trauma that continues to perpetuate emotions, "inner states of horror", and survival-driven coping strategies on an intergenerational basis $[7,8]$. With respect to the current conflict in eastern Ukraine, evidence from a small qualitative study of internally displaced women and children has found that the armed conflict was reported as contributing to a "significant deterioration of perceived mental health" for most respondents, many of whom reporting experiencing anxiety, depression, and stress [9].

While PTSD, anxiety and depression are more commonly researched among conflict-affected populations, a less researched outcome is somatic distress (SD), which was previously classified under somatoform disorders but is now known as somatic symptom disorder under the DSM-5 $[10,11]$. SD manifests as physical discomfort in the absence of a known underlying medical cause, producing symptoms such as insomnia or unexplained pain in the chest, limbs, or stomach. In addition to being burdensome for individuals, providing necessary treatment for the disorder often puts a strain on local health care services [12 - 14].

It is sometimes difficult to quantify SD as the types and meaning of somatic symptoms vary based on cultural beliefs and different health care contexts. In Ukraine, mental health is now recognized as playing an important role in overall well-being, although "attitudes toward people with mental illness can often be negative" $[9,15]$. Furthermore, somatic symptoms have not always been viewed through a biopsychosocial lens that recognizes the relationship between psychological stressors and physical ailments [16]. Following the Chernobyl nuclear disaster in 1986, those suffering from somatic symptoms were "dismissed locally with diagnoses such as 'radiophobia' or vegetative dystonia" [16]. Research on SD globally is further complicated by variation in the measurement of the disorder and a poor understanding of its pathophysiological mechanisms [18]. Despite these complexities, SD has been shown to be a valid construct from a cross-cultural perspective in studies conducted across low- and high-income settings $[13,19]$.

Risk factors for the development of SD include exposure to traumatic events, existing mental disorders, and socioeconomic deprivation, all of which are commonly elevated in conflictaffected populations. The importance of studying SD in traumatised populations has been highlighted, particularly from a transcultural perspective [20]. Such work highlights how SD can be generated by trauma associations, arousal, and catastrophic events. Despite this, there 
have only been a limited number of studies on SD with conflict-affected populations, particularly in low- and middle-income countries where the vast majority of these populations reside. The existing evidence base for lower-income regions includes a cross-sectional study conducted on civilian war survivors in Kosovo, a study on primary care patients in Bosnia and Herzegovina, and a cross-sectional survey of IDPs in the Republic of Georgia [11, 21, 22].

Past research across all settings, albeit limited, suggests that the overall burden of SD is large among conflict-affected populations and that SD hinders daily functioning across varying demographics $[11,23,24]$. A deeper understanding of the scope of this problem would be beneficial to key health system actors during efforts to provide required mental health and psychosocial support (MHPSS) services following humanitarian crises.

The overall aim of this study is to examine patterns of SD among IDPs in Ukraine. The objectives are: (1) to describe the prevalence of SD risk; (2) to examine the association between SD risk and mental disorders, trauma exposure, and sociodemographic characteristics; and (3) to describe trends in mental health care service utilisation for this population.

\section{Methods}

\section{Data collection}

Data were collected between March 2016 and May 2016 from a nationally representative sample of adult IDPs (excluding regions under the control of pro-Russian groups in eastern Ukraine) using a cross-sectional survey design. Participants were included if they were aged 18 years or above at the time of the survey and confirmed by a screening question to have been displaced from their homes due to war or armed violence. Participants were excluded if they had severe intellectual or mental impairments using predefined criteria related to behaviour, communication, and understanding (for which data collectors received training). Participants were also excluded if they appeared to be under the influence of alcohol or drugs as determined by the above criteria for behaviour, communication, and understanding.

To accurately represent IDP populations throughout the country, time-location sampling was employed across 25 Ukrainian oblasts [25,26]. This probabilistic sampling technique was developed for hard-to-reach populations and is increasingly used with dispersed, forciblydisplaced populations where traditional methods utilised for camp populations (such as cluster or straight random sampling) may no longer be employed. The method involves constructing time-location units representing likely dates, times, and locations where the target population can be interviewed [12]. For this study, respondent sampling occurred at locations that IDPs commonly frequent, such as humanitarian aid distribution centres, IDPspecific hostels, non-governmental organisations, and state service centres. Overall, recruitment involved visits to over 121 different public locations in addition to private locations such as respondents' residences or workplaces.

\section{Survey questionnaire and outcome measures}

The survey questionnaire was administered to study participants during an in-person interview. The main outcome was the presence of somatic symptoms measured using the 
Patient Health Questionnaire 15 (PHQ-15), which is an SD scale commonly administered across diverse settings [27]. The scoring followed standard guidelines, with each of the 15 items receiving a score from 0 ("not bothered at all" or "not at all") to 2 ("bothered a lot" or "nearly every day") to generate a total score out of 30 points [28]. Respondents with a PHQ15 score of 6 or more were considered at risk of SD [11,29]. Total SD scores were also used to categorise the potential severity of the disorder as minimal risk (0 to 4$)$, low risk (5 to 9 ), moderate risk (10 to 14$)$, or high risk $(\geq 15)$.

Other health outcomes were self-reported symptoms of anxiety, depression, post-traumatic stress, and functional disability. Anxiety symptoms over the past 2 weeks were measured using the Generalised Anxiety Disorder 7 (GAD-7) scale. Each item was scored from 0 to 3, with a maximum total of 21 points [30]. The recommended cut-off indicating at least moderate anxiety is a score of 10 or more [30,31]. Depressive symptoms over the past 2 weeks were assessed using the Patient Health Questionnaire 9 (PHQ-9), which contains 9 items each with scores ranging from 0 to 3 . The instrument has a suggested cut-off score of 10 or more, which indicates depression of at least moderate severity [32]. Post-traumatic stress symptoms (PTSS) over the past month were scored using the Post-Traumatic Stress Disorder Checklist for DSM-5 (PCL-5), which is a self-reported instrument that includes 20 items on PTSS [33]. Each item may receive a maximum score of 4 ("extremely" affected) to produce a total score of 80 . A score of 34 or higher is the recommended cut-off for this scale [34]. Functional disability was measured using the second version of the World Health Organization Disability Assessment Schedule (WHODAS 2.0). Each of the 12 items was scored and summed before being reweighted to a final score out of 100 as per WHO guidelines [35].

Basic demographic and socioeconomic variables were also included in the survey, along with questions on accessing mental health services. In addition, exposure to traumatic events was measured using the Life Events Checklist for DSM-5 (LEC-5), which records exposure to any of 16 traumatic events (plus any self-identified event not listed by the instrument) over the course of the respondent's lifetime [36]. No specific scoring procedure is recommended, with most studies examining the exposure type and number of traumatic events [11, 36 - 38].

The PHQ-15 instrument demonstrated strong internal reliability with a Cronbach's alpha score of 0.88. Reliability coefficients for the scales for anxiety, depression, and PTSS were $0.92,0.90$, and 0.95 , respectively. A separate mini survey on 110 respondents was also conducted to assess test-retest reliability for these scales, which showed strong intraclass correlation coefficients of $0.89,0.84$, and 0.83 , respectively. In addition, construct validity was high for these 3 measures (see Roberts et al. 2017 for more detailed information) [2].

The survey was piloted in English before being professionally adapted and translated into Ukrainian and Russian. The translation process was managed as to ensure reliability, validity, and cross-cultural equivalence of the survey instrument, as described in the literature [3941]. Trained interviewers from the Kiev International Institute of Sociology (KIIS) administered the questionnaires to respondents during face-to-face interviews at a mutually decided location (generally the respondent's home). Prior to the interview, respondents were informed about the study aims and terms of participation, received information sheets, and provided informed consent. . The Institutional Review Board at KIIS granted ethical approval for this study. 


\section{Data analysis}

The results of this study were generated using descriptive statistics and multivariate regression analysis. Backward stepwise logistic regression was performed to assess the association between SD risk and mental disorders, trauma exposure, and sociodemographic factors, with a dichotomous outcome of being at risk of SD (PHQ-15 score $\geq 6$ ). The procedure for backward stepwise regression involved constructing an initial model containing a full set of potential covariates identified by the study team and the published literature, and eliminating variables individually until a final model was fitted. The multivariate model adjusted for age, economic status, gender, self-reported depression and PTSS, and trauma exposure.

A linear regression model was used to determine the relationship between SD risk and functional disability, with weighted WHODAS 2.0 scores used as the continuous outcome variable. The model included the covariates of age, economic status, occupation, selfreported mental disorders, and trauma exposure. Multivariate logistic regression was also performed to discern associations between being at risk of SD and mental health care utilisation over the past year.

The threshold for statistical significance was set at $\mathrm{p}<0.05$. Adjustments were made to account for the survey sampling design with all study data weighted by oblast to reflect the nationwide distribution of IDPs. Data on characteristics of non-responders were not collected and so could not be factored into the analysis; however, the response rate was high at $89 \%$. All analyses were performed using Stata 14.

\section{Results}

The study sample was comprised of 2203 adult respondents throughout government-held areas in Ukraine, with an overall survey response rate of $89 \%$. Around two-thirds (68\%) of respondents were women and the remainder $(32 \%)$ were men. This skewed gender ratio aligns with past research on IDPs in Ukraine [42, 43]. The sample had a median age of 42 years and a mean age of 45.1 years. Only $22 \%$ of respondents were engaged in regular paid work and an additional 10\% were in irregular paid work. Almost two-thirds (59\%) perceived their household economic situation as bad or very bad while only $5 \%$ of households believed their economic status was good or very good. Eighty-six percent of respondents had been displaced for more than 12 months. For the mental health outcomes, 17\% met the published cut-offs for self-reported symptoms of anxiety, $22 \%$ for depression, and $26 \%$ for posttraumatic stress. Among those who were categorized as having self-reported anxiety, depression, or PTSS, the co-morbidity of SD risk was 80\%, 80\%, and 77\%, respectively. Additional sample characteristics are provided in Table 1.

In terms of exposure to traumatic events, $332(15 \%)$ respondents had experienced none of the events listed in the questionnaire, 455 (21\%) individuals experienced 1 event, 354 (16\%) experienced 2 events, 351 (16\%) experienced 3 events, 322 (15\%) experienced 4 events, and $380(17 \%)$ experienced 5 or more events at some point in their lives. The most common traumatic events experienced were life-threatening illness or injury $(n=354)$, fire or explosion $(n=638)$, severe human suffering $(n=931)$, any other very stressful event or experience $(n=1002)$, and combat or exposure to a war zone $(n=1570)$. 
For the outcome of SD, the mean SD score was 7.42 [95\% CI 7.18, 7.67]. Over half (55\%) of respondents were at risk of SD (PHQ-15 score $\geq 6$ ). Among those with a more significant burden of somatic symptoms, $18 \%$ were at risk of moderate severity SD and $13 \%$ were at risk of high severity SD. Additional data on SD risk are available in Table 2.

The multivariate logistic regression analysis revealed significant associations between the variables age, female gender, poor economic status, self-reported depression and PTSS, and multiple trauma exposures with being at risk of SD (Table 3). For trauma exposure, experiencing 1 or more events were all significantly associated with SD risk. The strongest association was for respondents who had experienced 5 or more traumatic events (OR 6.75, [95\% CI 3.78, 12.07], $\mathrm{p}<0.001)$. We also explored the linear association of cumulative trauma exposure with SD by treating trauma exposure as a continuous variable in the same multivariate model and the resultant OR was 1.30 ([95\% CI 1.18, 1.42] $(\mathrm{P}<.0001)$.

A separate multivariate regression analysis was also conducted for an outcome of being at risk of high severity SD (score $\geq 15$ ). This showed particularly strong associations with selfreported symptoms of depression (OR 7.21, [95\% CI 3.85, 13.49], $\mathrm{p}<0.001$ ) and posttraumatic stress (OR 3.10, [95\% CI 1.66, 5.81], $\mathrm{p}<0.001)$. Additional data on this regression analysis are available in Online Annex 1.

The association between SD risk and functional disability as a continuous outcome was significant $(\beta=5.48,[95 \%$ CI 3.88, 7.08], $\mathrm{p}<0.001)$, after adjusting for age, economic status, occupation, anxiety, self-reported depression and PTSS, and trauma exposure.

We examined patterns of SD risk among those self-reporting mental health concerns (anxiety, nervousness, depression, insomnia, or other emotional/behavioural problems) in the past year. Within this group of 1425 respondents, there were 915 individuals who were also at risk of SD, of whom 203 (22\%) sought care. The treatment modalities received by these care seekers were pharmacotherapy $(n=158,78 \%)$, psychosocial support $(n=115,57 \%)$, and counselling or psychotherapy $(n=84,41 \%)$. Some of these care seekers received more than one treatment modality. For the 430 respondents who were not at risk of SD, care-seeking behaviour was considerably lower with only $43(10 \%)$ attempting to obtain necessary care. Additional information is available in Figure 1.

For those individuals who did not have a mental disorder (self-reported symptoms of anxiety, depression, or post-traumatic stress using the screening instruments described above) but were at risk of SD, mental health care utilisation was also low. Only $40(13 \%)$ individuals in this group sought care while the remaining $255(87 \%)$ respondents did not.

We further examined the association between SD risk and the binary outcome of mental health care utilisation. In a multivariate model (adjusted for age, gender, economic status, self-reported symptoms of anxiety, depression, post-traumatic stress, and trauma exposure), being at risk for SD was not significantly associated with the use of mental health services. However, being at risk of high severity SD was significantly associated with mental health care utilisation $(\mathrm{OR}=2.32$, [95\% CI 1.33, 4.06], $\mathrm{p}=0.003)$.

\section{Discussion}


In recent years, there has been an increase in research on mental health during humanitarian crises, such as international conflict or natural disasters, in low- and middle-income countries $[44,45]$. However, the vast majority of this research focuses on common mental disorders such as anxiety, depression, and PTSD [5, 45 - 47]. In humanitarian settings, there remains a scarcity of research on other mental health conditions such as SD [48]. As many of these other disorders also have highly damaging effects on mental health and overall well-being, further research is required to identify these conditions of rising concern and dedicate appropriate resources towards them [48, 49].

The results of our study highlight the large risk of SD among IDPs in Ukraine, with over half of respondents at risk for the condition. This is even higher than the $42 \%$ prevalence of SD risk recorded among IDPs in the Republic of Georgia [11]. Among the respondents for the study of Georgian IDPs, $15 \%$ were at risk of moderate severity SD and 3\% were at risk of high severity SD [11]. In Ukraine, $18 \%$ of the study population were at risk of moderate severity SD, while $13 \%$ were at risk of high severity SD. This substantial proportion of respondents at risk of high severity SD has implications for both physical and mental health care utilisation in Ukraine. While the Ukrainian health system offers medical treatment free of charge for its citizens, awareness of primary and secondary care options for addressing the psychosomatic sequelae of trauma is limited. This suggests a gap in essential post-conflict health services and the need for further capacity building, particularly around the integration of evidence-based mental health care practices into Ukrainian primary care.

In our study, being at risk of SD was significantly associated with factors of self-reported depression and PTSS, increasing age, and multiple trauma exposures. These findings reflect conclusions from research conducted across diverse settings, including surveys of Georgian IDPs, Dutch primary care patients, Iraq war veterans, and American female trauma survivors $[11,28,50-55]$. Furthermore, in our sample, a separate linear regression analysis revealed a significant association between SD risk and increasing functional disability. Similar findings have been previously reported in Ethiopia and the Netherlands outside a humanitarian context $[56,57]$.

Despite our findings regarding the associations between SD risk and mental disorders, being at risk of SD was not significantly associated with mental health care utilisation when the regression model was adjusted for age, gender, economic status, and self-reported symptoms of anxiety, depression, and post-traumatic stress. However, there was an association between being at risk of high severity SD and use of mental health services, likely owing to the severity of the somatic symptoms. It is important to consider the more frequent care-seeking behaviour of people at risk of high severity SD when planning for health services postconflict to ensure that essential MHPSS services are available for those with more acute needs $[58-60]$.

The results of this study also highlight demographics that may require greater attention, including those who are female, of lower economic status, older, have experienced multiple traumatic events, and have other mental disorders such as depression or PTSD. For future health system planning and capacity building, these findings can be applied to ensure that limited resources are appropriately mobilised in addressing the risk of SD during the postconflict period $[61,62]$. It is crucial to consider less-researched mental conditions such as SD in health system planning so that MHPSS interventions are targeted to the precise needs of these populations. This is particularly the case in a setting such as Ukraine (and other regions 
affected by conflict and forced displacement) where health service availability is typically inadequate $[2,63,64]$.

Our study findings suggest that there needs to be strong awareness by health care providers of SD risk among IDPs. It also requires recognition of various underlying psychological needs given the high levels of mental disorders among the study population. This necessitates a strengthening of mental health care diagnosis and services for IDPs in Ukraine, particularly at the primary health care level [2]. In this regard, there is evidence that culturally sensitive and adapted psychological approaches such as cognitive behavioural therapy (CBT) can help in the management of various types of somatic symptoms and related sequelae of mental disorders [65 - 67]. Evidence has also shown that high quality social support is associated with decreased levels of SD and psychological distress during prolonged exile [68, 69].

\section{Limitations}

An important limitation of this study was the absence of a pre-interview medical evaluation for survey respondents. The PHQ-15 screening instrument for somatic symptoms, while itself robust and well-validated, is nonetheless not equipped to distinguish between symptoms that are physical or psychological in nature $[28,70]$. This eliminated the opportunity for a medical explanation of physical symptoms and advances the possibility that our findings overrepresented the true levels of SD in the study population. Moreover, we were unable to make definitive comparisons to the non-displaced Ukrainian population due to the lack of a control group in our survey design. A risk of selection bias was also present due to a lack of relevant data on non-responders, but a high survey response rate of $89 \%$ strongly mitigated this risk. Furthermore, the cross-sectional survey design precludes examining temporal trends in SD and causal relationships between SD and associated factors. The lack of data on SD incidence precluded our ability to make evidence-based recommendations for prevention strategies that could be generalised to populations in similar humanitarian settings. In addition, the questions we asked on health care utilisation were limited to mental health services due to the focus on mental health care in the broader study. As a result, we did not capture data on utilisation of physical health services which, given the clinical manifestations of SD, may have been much higher than use of mental health services. We may also not have captured all somatic symptoms specific to the cultural context in Ukraine and how they may act as idioms of distress, and further work should take place following approaches used elsewhere [29, 71, 72]. This includes the need for more in-depth studies to strengthen cultural interpretation of somatic symptoms and its presentation in Ukraine and other conflict-affected settings, including the validity of SD measures (as done for other outcomes among conflict-affected populations $[73,74]$.

\section{Conclusion}

This study highlights the high levels of SD risk among IDPs in Ukraine following the 2016 conflict. SD risk was strongly associated with the presence of select mental disorders and multiple traumatic events sustained over a lifetime. Individuals at risk of very severe SD were more likely to seek out mental health care, which raises important questions for those involved in health care planning and delivery in Ukraine. Additional research would assist in enhancing our understanding of SD and appropriate responses to addressing the disorder in conflict-affected populations. 


\section{Ethical standards}

All aspects of this study comply with institutional and national guidelines on research and human experimentation, in addition to the most recent revision of the Declaration of Helsinki.

\section{Conflicts of interest}

The authors have no conflicts of interest to declare. 
Table 1: Sample characteristics of respondents

\begin{tabular}{|c|c|c|c|}
\hline & \multicolumn{2}{|c|}{$\mathbf{N} \quad(\%)^{\ddagger}$} \\
\hline \multirow[t]{2}{*}{ Gender } & Men & 704 & $(31.9)$ \\
\hline & Women & 1499 & (68.1) \\
\hline \multirow[t]{4}{*}{ Age } & $18-29$ & 432 & $(19.6)$ \\
\hline & $30-44$ & 758 & $(34.4)$ \\
\hline & $45-59$ & 522 & $(23.7)$ \\
\hline & $\geq 60$ & 490 & (22.3) \\
\hline \multirow[t]{3}{*}{ Education } & Primary complete or secondary incomplete & 114 & $(5.2)$ \\
\hline & Secondary complete or tertiary incomplete & 1295 & $(58.9)$ \\
\hline & Tertiary & 790 & $(35.9)$ \\
\hline \multirow[t]{3}{*}{ Marital Status } & Married & 1149 & $(52.7)$ \\
\hline & Divorced, widowed, or separated & 590 & (27.1) \\
\hline & Single & 440 & $(20.2)$ \\
\hline \multirow[t]{7}{*}{ Occupation } & Paid work & 766 & $(35.0)$ \\
\hline & Regular & 489 & $(22.4)$ \\
\hline & Irregular & 216 & (9.8) \\
\hline & Self-employed & 61 & $(2.8)$ \\
\hline & Seeking work (unemployed) & 391 & $(17.9)$ \\
\hline & Housewife or maternity leave & 239 & $(10.9)$ \\
\hline & Other (volunteer, student, retired) & 791 & $(36.2)$ \\
\hline \multirow{3}{*}{$\begin{array}{l}\text { Economic } \\
\text { Status }\end{array}$} & Good or very good & 110 & $(5.2)$ \\
\hline & Average & 755 & $(35.7)$ \\
\hline & Bad or very bad & 1251 & $(59.1)$ \\
\hline \multirow{3}{*}{$\begin{array}{l}\text { Time } \\
\text { Displaced }\end{array}$} & $\leq 12$ months & 293 & $(13.5)$ \\
\hline & 13 to 18 months & 927 & $(42.7)$ \\
\hline & $>18$ months & 953 & $(43.9)$ \\
\hline \multirow{2}{*}{$\begin{array}{l}\text { Official IDP } \\
\text { Status }\end{array}$} & Yes & 1989 & $(91.7)$ \\
\hline & No & 179 & (8.3) \\
\hline \multirow[t]{3}{*}{ Mental Health } & Anxiety* & 337 & $(17.5)$ \\
\hline & Depression** $^{* *}$ & 414 & (22.1) \\
\hline & PTSS $^{* * *}$ & 450 & (26.2) \\
\hline
\end{tabular}

Notes: 
$\ddagger$ Percentages are shown relative to the total number of responses recorded per questionnaire item. For the mental disorders, these denominators are $\mathrm{N}=1929$ (anxiety), $\mathrm{N}=1874$

(depression), and $\mathrm{N}=1719$ (PTSS).

*Based on GAD-7 score $\geq 10$

** Based on PHQ-9 score $\geq 10$

*** Based on PCL-5 score $\geq 34$ 
Table 2: Risk and levels of SD

N (\%)

\begin{tabular}{llrl}
\hline Risk of SD* & Yes & 1142 & $(55.1)$ \\
& No & 930 & $(44.9)$ \\
\hline SD Severity** & Minimal risk & 778 & $(37.5)$ \\
& Low risk & 642 & $(31.0)$ \\
& Moderate risk & 377 & $(18.2)$ \\
& High risk & 275 & $(13.3)$ \\
\hline
\end{tabular}

Notes:

${ }^{*} \mathrm{~A} P H Q-15$ score of 6 or more classified respondents as being at risk of SD.

${ }^{*}$ Levels of SD severity were determined using the following scale for PHQ-15 scores: minimal risk (0 to 4), low risk (5 to 9), moderate risk (10 to 14 ), and high risk ( $\geq 15)$. 


\section{Table 3: Bivariate and multivariate analyses of factors associated with being at risk of SD}

\begin{tabular}{|c|c|c|c|c|c|c|c|c|c|c|}
\hline \multirow{3}{*}{$\begin{array}{l}\text { Gender } \\
\text { Men }\end{array}$} & \multirow[t]{2}{*}{$\mathbf{N}$} & \multirow[t]{2}{*}{$(\%)^{\ddagger}$} & \multicolumn{4}{|c|}{ Bivariate Analysis } & \multicolumn{4}{|c|}{ Multivariate Analysis } \\
\hline & & & \multirow{2}{*}{$\begin{array}{l}\text { OR } \\
\text { ref }\end{array}$} & \multicolumn{2}{|c|}{$[95 \% \mathrm{Cl}]$} & $p$-value & OR & \multicolumn{2}{|c|}{$[95 \% \mathrm{Cl}]$} & $p$-value \\
\hline & 704 & $(31.9)$ & & & & & ref & & & \\
\hline Women & 1499 & $(68.1)$ & 1.96 & {$[1.56 ;$} & 2.47] & $<0.001$ & 2.01 & {$[1.45 ;$} & 2.80] & $<0.001$ \\
\hline \multicolumn{11}{|l|}{ Age } \\
\hline (continuous) & 2203 & $(100.0)$ & 1.06 & {$[1.05$} & $1.07]$ & $<0.001$ & 1.06 & {$[1.04$} & 1.07] & $<0.001$ \\
\hline \multicolumn{11}{|l|}{ Economic Status* } \\
\hline Good or very good & 110 & $(5.2)$ & ref & & & & ref & & & \\
\hline Average & 755 & $(35.7)$ & 3.95 & {$[2.18 ;$} & 7.14] & $<0.001$ & 3.13 & {$[1.31 ;$} & 7.47] & 0.010 \\
\hline Bad or very bad & 1251 & $(59.1)$ & 8.52 & {$[4.74$} & 15.3] & $<0.001$ & 3.72 & {$[1.55$} & 8.94] & 0.003 \\
\hline \multicolumn{11}{|l|}{ Mental Disorders } \\
\hline Depression & 414 & (22.1) & 8.33 & {$[5.82$} & 11.94] & $<0.001$ & 2.88 & {$[1.72 ;$} & 4.80] & $<0.001$ \\
\hline PTSS & 450 & $(26.2)$ & 7.80 & {$[5.68 ;$} & 10.70] & $<0.001$ & 3.19 & {$[2.04$} & 4.98] & $<0.001$ \\
\hline \multicolumn{11}{|l|}{ Trauma Exposure ${ }^{* *}$} \\
\hline No events & 332 & $(15.1)$ & ref & & & & ref & & & \\
\hline 1 event & 455 & (20.7) & 1.86 & {$[1.31$} & 2.64] & $<0.001$ & 1.67 & {$[0.98$} & 2.84] & 0.058 \\
\hline 2 events & 354 & $(16.1)$ & 2.88 & {$[1.98 ;$} & 4.17] & $<0.001$ & 3.93 & [2.36; & $6.55]$ & $<0.001$ \\
\hline 3 events & 351 & $(16.0)$ & 2.40 & {$[1.64 ;$} & 3.52] & $<0.001$ & 2.36 & {$[1.40 ;$} & 3.97] & $<0.001$ \\
\hline 4 events & 322 & (14.7) & 3.08 & {$[2.04 ;$} & $4.66]$ & $<0.001$ & 2.70 & {$[1.50 ;$} & 4.87] & $<0.001$ \\
\hline $5+$ events & 380 & $(17.3)$ & 8.34 & {$[5.36 ;$} & 12.97] & $<0.001$ & 6.75 & {$[3.78 ;$} & 12.07] & $<0.001$ \\
\hline
\end{tabular}

Notes:

$\ddagger$ Percentages are shown relative to the total number of responses recorded per questionnaire item.

$\mathrm{OR}=$ odds ratios (adjusted in the multivariate analyses)

$95 \% \mathrm{Cl}=95 \%$ confidence interval

SD risk $=P H Q-15$ score $\geq 6$

* To confirm the overall association of the Economic Status parameter on SD (i.e. rather than only the individual categorical variables within Economic Status), a Wald test was conducted which confirmed its significance in the overall model ( $P=0.0005)$.

** To confirm the overall association of the Trauma Exposure parameter on SD (i.e. rather than only the individual categorical variables within Economic Status), a Wald test was conducted which confirmed its significance in the overall model $(P<0.0001)$. 
Figure 1: Care-seeking behaviour categorised by being at risk of SD

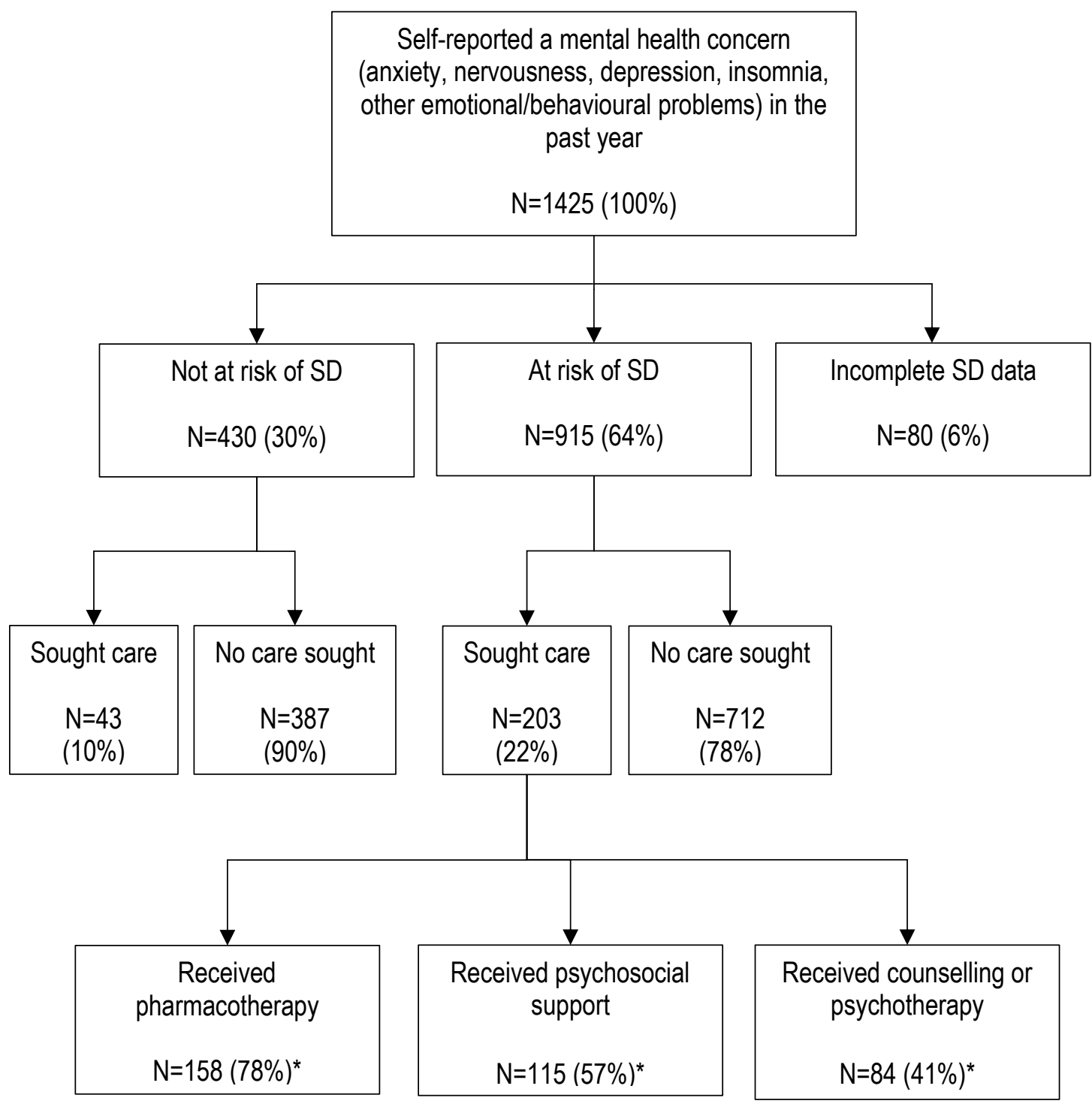

Note:

*Some care seekers received more than one treatment modality. 
Online Annex 1: Multivariate analysis of factors associated with being at risk of high severity SD

Multivariate Analysis

OR $\quad[95 \% \mathrm{Cl}] \quad \mathrm{p}$-value

Age

(continuous)

$1.04 \quad[1.02 ; 1.05] \quad<0.001$

Mental Disorders

Depression

$7.21 \quad[3.85 ; 13.49] \quad<0.001$

PTSS

$3.10 \quad[1.66 ; 5.81] \quad<0.001$

Trauma Exposure

No events

ref

1 event

$1.63 \quad[0.58 ; 4.59] \quad 0.352$

2 events

$3.82 \quad[1.44 ; 10.10] \quad 0.007$

3 events

2.78

$[1.01 ; 7.66] \quad 0.048$

4 events

$2.69 \quad[1.03 ; 7.06] \quad 0.044$

$\geq 5$ events

5.24

$[2.15 ; 12.76]<0.001$

Notes:

$\mathrm{OR}=$ odds ratios (adjusted)

$95 \% \mathrm{Cl}=95 \%$ confidence interval 


\section{References}

[1] Woroniecka-Krzyzanowska D, Palaguta N. Internally displaced persons and elections under military conflict in Ukraine. Journal of Refugee Studies. 2017 Mar; 30(1): 27-46.

[2] Roberts B, Makhashvili N, Javakhishvili J, Karachevsky A, Kharchenko N, Shpiker M, Richardson E. Mental health care utilisation among internally displaced persons in Ukraine: results from a nation-wide survey. Epidemiology and Psychiatric Sciences. 2017 Jul; 1-12.

[3] Miller KE, Rasmussen A. War exposure, daily stressors, and mental health in conflict and post-conflict settings: bridging the divide between trauma-focused and psychosocial frameworks. Social Science and Medicine. 2010 Jan; 70(1): 7-16.

[4] Siriwardhana C, Adikari A, Pannala G, Siribaddana S, Abas M, Sumathipala A, Stewart R. Prolonged internal displacement and common mental disorders in Sri Lanka: the COMRAID study. PLoS One. 2013 May; 8(5): e64742.

[5] de Jong JT, Komproe IH, van Ommeren M. Common mental disorders in postconflict settings. The Lancet. 2003 Jun; 361(9375): 2128-2130.

[6] Klymenko L. The Holodomor law and national trauma construction in Ukraine. Canadian Slavonic Papers. 2016 Oct; 58(4): 341-361.

[7] Bezo B, Maggi S. Living in "survival mode": intergenerational transmission of trauma from the Holodomor genocide of 1932-1933 in Ukraine. Social Science and Medicine. 2015 Apr; 134: 87-94.

[8] Bezo B, Maggi S. The intergenerational impact of the Holodomor genocide on gender roles, expectations and performance: the Ukrainian experience. Annals of Psychiatry and Mental Health. 2015 Apr; 3(3): 1030.

[9] Nidzvetska S, Rodriguez-Llanes JM, Aujoulat I, Cuesta JG, Tappis H, van Loenhout JAF, Guha-Sapir D. Maternal and child health of internally displaced persons in Ukraine: a qualitative study. International Journal of Environmental Research and Public Health. 2017 Jan; 14(1): 54.

[10] Morina N, Ford JD, Risch AK, Morina B, Stangier U. Somatic distress among Kosovar civilian war survivors: relationship to trauma exposure and the mediating role of experiential violence. Social Psychiatry and Psychiatric Epidemiology. 2010 Dec; 45(12): 1167-1177.

[11] Comellas RM, Makhashvili N, Chikovani I, Patel V, McKee M, Bisson J, Roberts B. Patterns of somatic distress among conflict-affected persons in the Republic of Georgia. Journal of Psychosomatic Research. 2015 May; 78(5): 466-471.

[12] Barsky AJ, Orav EJ, Bates DW. Somatization increases medical utilization and costs independent of psychiatric and medical comorbidity. Archives of General Psychiatry. 2005 Aug; 62(8): 903-910. 
[13] Gureje O, Simon GE, Ustun TB, Goldberg DP. Somatization in cross-cultural perspective: a World Health Organization study in primary care. American Journal of Psychiatry. 1997 Jul; 154(7): 989-995.

[14] Reid S, Wessely S, Crayford T, Hotopf M. Frequent attenders with medically unexplained symptoms: service use and costs in secondary care. British Journal of Psychiatry. 2002 Mar; 180: 248-253.

[15] International Medical Corps. Mental health in transition: Assessment and guidance for strengthening integration of mental health into primary health care and community-based service platforms in Ukraine. Updated 31 Oct 2017 [cited 15 Oct 2018]. Available from: http://documents.worldbank.org/curated/en/310711509516280173/pdf/120767-WP-RevisedWBGUkraineMentalHealthFINALwebvpdfnov.pdf

[16] Bromet EJ, Gluzman S, Schwartz JE, Goldgaber D. Somatic symptoms in women 11 years after the Chornobyl accident: prevalence and risk factors. Environmental Health Perspectives. 2002 Aug; 110(4): 625-629.

[17] Cwikel J, Abdelgani A, Goldsmith JR, Quastel M, Yevelson II. Two-year follow-up study of stress-related disorders among immigrants to Israel from the Chernobyl area. Environmental Health Perspectives. 1997 Dec; 105(6): 1545-1550.

[18] Creed F, Barsky A. A systematic review of the epidemiology of somatisation disorder and hypochondriasis. Journal of Psychosomatic Research. 2004 Apr; 56(4): 391-408.

[19] Bagayogo IP, Interian A, Escobar JI. Transcultural aspects of somatic symptoms in the context of depressive disorders. Advances in Psychosomatic Medicine. 2013; 33: 64-74.

[20] Hinton DE, Hofmann SG, Pitman RK, Pollack MH, Barlow DH. The panic attack posttraumatic stress disorder model: applicability to orthostatic panic among Cambodian refugees. Cognitive Behaviour Therapy. 2008 May; 37(2): 101-116.

[21] Broers T, Hodgetts G, Batic-Majanovic O, Petrovic V, Hasanagic M, Godwin M. Prevalence of mental and social disorders in adults attending primary care centers in Bosnia and Herzegovina. Croatian Medical Journal. 2006 Jun; 47(3): 478-484.

[22] Morina N, Ford JD, Risch AK, Morina B, Stangier U. Somatic distress among Kosovar civilian war survivors: relationship to trauma exposure and the mediating role of experiential avoidance. Social Psychiatry and Psychiatric Epidemiology. 2010 Dec; 45: 1167-1177.

[23] Cerutti R, Spensieri V, Valastro C, Presaghi F, Canitano R, Guidetti V. A comprehensive approach to understand somatic symptoms and their impact on emotional and psychosocial functioning in children. PLoS One. 2017 Feb; 12(2): e0171867.

[24] Harris AM, Orav EJ, Bates DW, Barsky AJ. Somatization increases disability independent of comorbidity. Journal of General Internal Medicine. 2009 Feb; 24(2): 155161.

[25] Semaan S. Time-space sampling and respondent-driven sampling with hard-to-reach populations. Methodological Innovations Online. 2010; 5(2): 60-75. 
[26] Karon JM, Wejnert C. Statistical methods for the analysis of time-location sampling data. Journal of Urban Health. 2012 Jun; 89(3): 565-586.

[27] Kocalevent R-D, Hinz A, Brahler E. Standardization of a screening instrument (PHQ-

15) for somatization disorder in the general population. BMC Psychiatry. 2013 Mar; 13: 91.

[28] Kroenke K, Spitzer RL, Williams JB. The PHQ-15: validity of a new measure for evaluating the severity of somatic symptoms. Psychosomatic Medicine. 2002 Mar/Apr; 64(2): 258-266.

[29] van Ravesteijn H, Wittkampf K, Lucassen P, van de Lisdonk E, van den Hoogen H, van Weert H, Huijser J, Schene A, van Weel C, Speckens A. Detecting somatoform disorders in primary care with the PHQ-15. Annals of Family Medicine. 2009 May/Jun; 7(3): 232-238.

[30] Lowe B, Decker O, Muller S, Brahler E, Schellberg D, Herzog W, Herzberg PY. Validation and standardization of the Generalized Anxiety Disorder Screener (GAD-7) in the general population. Medical Care. 2008 Mar; 46(3): 266-274.

[31] Spitzer RL, Kroenke K, Williams JB, Lowe B. A brief measure for assessing generalized anxiety disorder: the GAD-7. Archives of Internal Medicine. 2006 May; 166(10): 1092-1097.

[32] Kroenke K, Spitzer RL, Williams JB. The PHQ-9: validity of a brief depression severity measure. Journal of General Internal Medicine. 2001 Sep; 16(9): 606-613.

[33] Blevins CA, Weathers FW, Davis MT, Witte TK, Domino JL. The posttraumatic stress disorder checklist for DSM-5 (PCL-5): development and initial psychometric evaluation. Journal of Traumatic Stress. 2015 Dec; 28(6): 489-498.

[34] Ashbaugh AR, Houle-Johnson S, Herbert C, El-Hage W, Brunet A. Psychometric validation of the English and French versions of the posttraumatic stress disorder checklist for DSM-5 (PCL-5). PLoS One. 2016 Oct; 11(10): e0161645.

[35] World Health Organization. WHO Disability Assessment Schedule 2.0 (WHODAS 2.0). Updated 4 Sep 2017 [cited 15 Sep 2017]. Accessed from:

http://www.who.int/classifications/icf/more_whodas/en/

[36] National Center for PTSD. Life Events Checklist for DSM-5 (LEC-5). Updated 11 Apr 2017 [cited 15 Sep 2017]. Accessed from:

https://www.ptsd.va.gov/professional/assessment/te-measures/life_events_checklist.asp

[37] Gray MJ, Litz BT, Hsu JL, Lombardo TW. Psychometric properties of the Life Events Checklist. Assessment. 2004 Dec; 11(4): 330-341.

[38] Bae H, Kim D, Koh H, Kim Y, Park JS. Psychometric properties of the Life Events Checklist - Korean version. Psychiatry Investigation. 2008 Sep; 5(3): 163-167.

[39] Beaton DE, Bombardier C, Guillemin F, Ferraz MB. Guidelines for the process of crosscultural adaptation of self-report measures. Spine. 2000 Dec; 25(24): 3186-3191. 
[40] Cha E-S, Kim KH, Erlen JA. Translation of scales in cross-cultural research: issues and techniques. Journal of Advanced Nursing. 2007 May; 58(4): 386-395.

[41] van Ommeren M, Sharma B, Thapa S, Makaju R, Prasain D, Bhattarai R, de Jong J. Preparing instruments for transcultural research: use of the translation monitoring form with Nepali-speaking Bhutanese refugees. Transcultural Psychiatry. 1999 Sep; 36(3): 285-301.

[42] UNICEF. Elderly assessment in government controlled areas of Donetsk and Luhansk oblasts. Updated 29 Feb 2016 [cited 15 Sep 2017]. Available from:

https://www.humanitarianresponse.info/system/files/documents/files/oldpeople_assessment_c dc_gca_presentation.pdf

[43] UNOCHA. 2017 Humanitarian needs overview. Updated Nov 2016 [cited 15 Sept 2017]. Available from:

https://www.humanitarianresponse.info/system/files/documents/files/ukraine_humanitarian_n eeds_overview_2017_eng.pdf

[44] Blanchet K, Sistenich V, Ramesh A, Frison S, Warren E, Smith J, Hossain M, Knight A, Lewis C, Post N, Woodward A, Ruby A, Dahab M, Pantuliano S, Roberts B. An evidence review of research on health interventions in humanitarian crises. Updated 22 Oct 2015 [cited 15 Sep 2017]. Available from: http://www.elrha.org/wp-content/uploads/2015/01/EvidenceReview-22.10.15.pdf

[45] Bangpan M, Dickson K, Felix L, Chiumento A. The impact of mental health and psychosocial support interventions on people affected by humanitarian emergencies: a systematic review. Humanitarian Evidence Programme. 2017 Mar. Oxford: Oxfam Great Britain.

[46] Neria Y, Nandi A, Galea S. Post-traumatic stress disorder following disasters: a systematic review. Psychological Medicine. 2008 Apr; 38(4): 467-480.

[47] Siriwardhana C, Stewart R. Forced migration and mental health: prolonged internal displacement, return migration and resilience. International Health. 2013 Mar; 5(1): 19-23.

[48] Tol WA, Barbiu C, Galapatti A, Silove D, Betancourt TS, Souza R, Golaz A, van Ommeren M. Mental health and psychosocial support in humanitarian settings: linking practice and research. The Lancet. 2011 Oct; 378(9802): 1581-1591.

[49] de Moraes Weintraub ACA, Garcia MG, Birri E, Severy N, Ferir MC, Tayler-Smith K, Nadera DP, van Ommeren M. Not forgetting severe mental disorders in humanitarian emergencies: a descriptive study from the Philippines. International Health. 2016 Sep; 8(5): 336-344.

[50] de Waal MW, Arnold IA, Eekhof JA, van Hemert AM. Somatoform disorders in general practice: prevalence, functional impairment and comorbidity with anxiety and depressive disorders. British Journal of Psychiatry. 2004 Jun; 184: 470-476.

[51] Hoge CW, Terhakopian A, Castro CA, Messer SC, Engel CC. Association of posttraumatic stress disorder with somatic symptoms, health care visits, and absenteeism among Iraq war veterans. American Journal of Psychiatry. 2007 Jan; 164(1): 150-153. 
[52] Kroenke K. Somatic symptoms and depression: a double hurt. Primary Care Companion to the Journal of Clinical Psychiatry. 2005; 7(4): 148-149.

[53] Shidhaye R, Mendenhall E, Sumathipala K, Sumathipala A, Patel V. Association of somatoform disorders with anxiety and depression in women in low- and middle-income countries: a systematic review. International Review of Psychiatry. 2013 Feb; 25(1): 65-76.

[54] McCall-Hosenfeld J, Winter M, Heeren T, Liebschutz JM. The association of interpersonal trauma with somatic symptom severity in a primary care population with chronic pain: exploring the role of gender and the mental health sequelae of trauma. Journal of Psychosomatic Research. 2014 Sep; 77(3): 196-204.

[55] Bogner HR, Shah P, de Vries HF. A cross-sectional study of somatic symptoms and the identification of depression among elderly primary care patients. Primary Care Companion to the Journal of Clinical Psychiatry. 2009; 11(6): 285-291.

[56] Senturk V, Hanlon C, Medhin G, Dewey M, Araya M, Alem A, Prince M, Stewart R. Impact of perinatal somatic and common mental disorder symptoms on functioning in Ethiopian women: the P-MaMiE population-based cohort study. Journal of Affective Disorders. 2012 Feb; 136(3-3): 340-349.

[57] van der Leeuw G, Gerrits MJ, Terluin B, Numans ME, van der Feltz-Cornelis CM, van der Horst HE, Penninx BW, van Marwijk HW. The association between somatization and disability in primary care patients. Journal of Psychosomatic Research. 2015 Aug; 79(2): 117-122.

[58] Da Silva RB, Contandriopoulos A-P, Pineault R, Tousignant P. A global approach to evaluation of health services utilization: concepts and measures. Healthcare Policy. 2011 May; 6(4): e106-e117.

[59] Wang PS, Gruber MJ, Powers RE, Schoenbaum M, Speier AH, Wells KB, Kessler RC. Mental health service use among Hurricane Katrina survivors in the eight months after the disaster. Psychiatric Services. 2007 Nov; 58(11): 1403-1411.

[60] Rodriguez JJ, Kohn R. Use of mental health services among disaster survivors. Current Opinion in Psychiatry. 2008 Jul; 21(4): 370-378.

[61] Kruk ME, Rockers PC, Williams EH, Varpilah ST, Macauley R, Saydee G, Galea S. Availability of essential health services in post-conflict Liberia. Bulletin of the World Health Organization. 2010 Jul; 88(7): 527-534.

[62] Nagai M, Abraham S, Okamato M, Kita E, Aoyama A. Reconstruction of health service systems in the post-conflict Northern Province in Sri Lanka. Health Policy. 2007 Sep; 83(1): 84-93.

[63] Chikovani I, Makhashvili N, Gotsadze G, Patel V, McKee M, Uchaneishvili M, Rukhadze N, Roberts B. Health service utilization for mental, behavioural and emotional problems among conflict-affected population in Georgia: a cross-sectional study. PLoS One. 2015 Apr; 10(4): e0122673. 
[64] Ventevogel P, van Ommeren M, Schilperoord M, Saxena S. Improving mental health care in humanitarian emergencies. Bulletin of the World Health Organization. 2015 Oct; 93(10): 666-666A.

[65] Hinton DE, Otto MW. Symptom presentation and symptom meaning among traumatized Cambodian refugees: relevance to a somatically focused cognitive-behavior therapy. Cognitive and Behavioral Practice. 2006 Nov; 13(4): 249-260.

[66] Hinton DE, Pich V, Chhean D, Safren SA, Pollack MH. Somatic-focused therapy for traumatized refugees: treating posttraumatic stress disorder and comorbid neck-focused panic attacks among Cambodian refugees. Psychotherapy (Chicago, Illinois). 2006 Winter; 43(4): 491-505.

[67] Patel V, Sumathipala A. Psychological approaches to somatisation in developing countries. Advances in Psychiatric Treatment. 2005 Dec; 12(1): 54-62.

[68] Fazel M, Reed RV, Panter-Brick C, Stein A. Mental health of displaced and refugee children resettled in high-income countries: risk and protective factors. The Lancet. 2012 Jan; 379(9812): 250-265.

[69] Kohli A, Perrin N, Mpanano RM, Case J, Murhula CM, Binkurhorhwa AK, Mirindi AB, Banywesize JH, Bufole NM, Ntwali EM, Glass N. Social interaction in the aftermath of conflict-related trauma experiences among women in Walungu Territory, Democratic Republic of Congo. Global Public Health. 2015 Jan; 10(1): 55-70.

[70] de Vroege L, Hoedeman R, Nuyen J, Sijtsma K, van der Feltz-Cornelis CM. Validation of the PHQ-15 for somatoform disorder in the occupational health care setting. Journal of Occupational Rehabilitation. 2012 Mar; 22(1): 51-58.

[71] Hinton DE, Hinton SD, Loeum RJ, Pich V, Pollack MH. The 'multiplex model' of somatic symptoms: application to tinnitus among traumatized Cambodian refugees.

Transcultural Psychiatry. 2008 Jun; 45(2): 287-317.

[72] Hinton DE, Otto MW. Symptom presentation and symptom meaning among traumatized Cambodian refugees: relevance to a somatically focused cognitive-behavior therapy.

Cognitive and Behavioral Practice. 2006 Nov; 13(4): 249-260.

[73] Jayawickreme, N., Verkuilen, J., Jayawickreme, E., Acosta, K., \& Foa, E. B. (2017). Measuring Depression in a Non-Western War-Affected Displaced Population: Measurement Equivalence of the Beck Depression Inventory. Frontiers in psychology, 8, 1670.

[74] Roberts, B., Browne, J., Ocaka, K. F., Oyok, T., \& Sondorp, E. (2008). The reliability and validity of the SF-8 with a conflict-affected population in northern Uganda. Health and quality of life outcomes, 6, 108. 